\title{
A constituição do estranho em Bartleby, the Scrivener: a Story of Wall Street
}

Carlos Henrique Francisco de Amorim Santos

\section{Resumo:}

A novela de Herman Melville, Bartleby, the Scrivener: a Story of Wall Street, tem notório destaque entre as obras do autor e tem fascinado autores, filósofos e o público leitor diante do desafio de interpretá-la. Nosso artigo busca analisar a novela de Melville à luz dos textos de Deleuze e Freud, tendo como foco a constituição do "estranho" dentro da novela e seu efeito na construção da obra literária norte-americana.

Palavras-chave: Estranho - Norte-americano - Absurdo - Herman Melville 


\section{Algumas considerações}

Quando Herman Melville escrevia Bartleby, the Scrivener: a Story of Wall Street, publicado em I853 na Putnam's Magazine, ele não fazia ideia de que sua história faria tanto barulho e levantaria diversas hipóteses sobre os seus significados. Algumas das interpretações dessa obra estão ligadas diretamente à vida de Melville enquanto escritor e romancista. Antes da publicação da novela, ${ }^{\mathrm{I}}$ o autor havia passado por duas rejeições de seus romances por parte da crítica e do público. Moby Dick, romance que o próprio Melville considerava sua obra-prima, foi um deles. O jornal inglês London Athenaum descreveu seu estilo em Moby Dick como: "desfigurado por um inglês maluco (ao invés de ruim) e sua catástrofe é apressadamente, fracamente e obscuramente organizada". ${ }^{2}$ Como o romance fora publicado primeiramente na Inglaterra, sua má fama criada pela crítica inglesa já estava consolidada ao chegar na América, e a crítica americana, salvo raras exceções, apenas concordou e reiterou a rejeição. Anos mais tarde, a novela ganharia a imensa notoriedade que possui hoje por tratar de temas tão a frente de seu próprio tempo e tão presentes na ideologia da cultura norte-americana.

Alguns críticos sugerem que Bartleby, the Scrivener não é nada mais que uma resposta direta, quase biográfica, de Melville às críticas e concepções formais da literatura que interferem na apropriada significação da obra literária, como havia ocorrido com o seu romance. "I would prefer not to", frase repetida diversas vezes pelo personagem central, Bartleby, a cada pedido que seu chefe e narrador da história faz, seria a própria voz de Melville negando qualquer adaptação aos parâmetros formais da literatura.

No entanto, é possível encontrarmos as mais variadas interpretações sobre essa novela. A análise e interpretação aqui sugeridas se aproximam muito mais do campo psicanalítico e filosófico do que de um campo essencialmente biográfico, embora não destoe totalmente deste. A base deste ensaio se concentra principalmente nos textos "Bartleby; or, the Formula" (I997a), do filósofo Deleuze, no "O estranho" (I9I9), de Freud, e na própria novela de Herman Melville, publicada em I843.

\footnotetext{
I Apesar de comumente tida como shortstory (conto), a longa extensão e a presença de capítulos na obra faz com que ela se aproxime mais, em termos formais, do gênero "novela".

2 "Disfgured by mad (rather than bad) English; and its catastrophe is hastily, weakly, and obscurely managed." In: The Life and Works of Herman Melville. 〈http://www. melville.org/melville.htm〉. Acessado em: I4 out. 2013. Todas as traduções neste artigo são nossas.
} 


\section{O início}

Uma das mais importantes contribuições dos muitos textos sobre a novela de Melville vem do filósofo Deleuze em seu texto "Bartleby; or, the Formula" (DELEUZE I997a, pp. 68-90), no qual o autor busca desvencilhar toda a problemática que envolve a novela. Apesar de Deleuze iniciar sua jornada analítica tratando aspectos linguísticos do jargão usado pela personagem Bartleby, o "I would prefer not to" dito por ele a todo e qualquer pedido, iniciaremos abordando o texto de Deleuze de outro ponto, onde este trata do narrador da história, o advogado.

O advogado, narrador sem nome, inicia a novela apresentando-se e dizendo ter a intenção de contar a história de Bartleby, seu ex-funcionário e escrivão. No entanto, antes de tratar dessa personagem, o narrador diz achar pertinente falar um pouco de si próprio, de onde ele trabalha e da sua vida em geral, "because some such description is indispensable to an adequate understanding of the chief character about to be presented". É com essa mesma lógica que Deleuze (I997a) justifica o comportamento estranho de Bartleby, dizendo ser impossível não levarmos em conta o comportamento estranho do próprio narrador: "Talvez Bartleby seja o louco, o demente, o psicótico (uma desordem inata e incurável da alma). Mas como sabê-lo, se não se levam em conta as anomalias do advogado que se comporta o tempo todo de modo muito esquisito?" (id. I997b, p. 87).

Antes de prosseguirmos, é interessante lembrarmos que o comportamento estranho de Bartleby consiste em enunciar a frase "Preferiria não fazê-lo" ${ }^{3}$ diante de, primeiramente, os pedidos feitos pelo seu chefe (narrador) no escritório em que trabalham, mas que, posteriormente, se torna uma "compulsão" dita para tudo e em qualquer circunstância. Como seu chefe, o advogado fica perplexo diante da resposta ao seu pedido, resposta esta que não é uma afirmação, muito menos uma negação. Como afirma Deleuze, "Bartleby não recusa, mas tão pouco aceita, ele avança e retrocede nesse avanço, se expõe um pouco num leve recuo da fala" (id. ibid., p. 82).

Esta é a "formula" mencionada no título do texto de Deleuze. "I would prefer not to" elimina a possibilidade de preferir algo, assim como de não preferir. A personagem permanece assim quase que num limbo sem vida ou preferência. O filósofo também nos chama a atenção para os aspectos linguísticos e semânticos da expressão de Bartleby. Ao preferir algo, entramos num campo de

3 "I prefer not to" (MELVILLE, I856). 
comparação, se prefere doce ao salgado, frio ao quente, vermelho ao azul. No entanto, Bartleby simplesmente "prefere não", prefere nada a nada. Podemos denominar o comportamento de Bartleby como sendo de uma extrema resiliência e passividade em relação à realidade ao seu redor. A realidade demanda uma série de coisas a Bartleby, e este simplesmente prefere não se mover. Tal comportamento, além de chocar o narrador-personagem, inspira alguns comentários deste: "Nada irrita tanto uma pessoa séria quanto uma resistência passiva". 4

Apesar do comentário, o autor insiste em sua posição "misericordiosa" para com Bartleby: "Pobre sujeito!, pensava eu, ele não tem a intenção de fazer mal algum; está claro que ele não pretende ser insolente; sua aparência evidencia suficientemente que suas excentricidades são involuntárias". ${ }^{5}$ Guardemos esse comentário do narrador a respeito da aparência de Bartleby, suas excentricidades e a pena que sente por este, pois ele será útil alguns trechos à frente. É bem verdade que Bartleby e suas atitudes ganham um aspecto totalmente estranho dentro da narrativa, mas lembremos que todo esse comportamento estranho é visto através dos olhos do narrador, o qual, como Deleuze já afirmou, tem um comportamento tão estranho quanto Bartleby (como veremos adiante), que deve ser levado em consideração.

Cabe aqui, no entanto, definirmos primeiramente o que seria "estranho". Para isso, recorremos ao esclarecedor ensaio de Freud a respeito do assunto. "O estranho" levanta uma série de questões concernentes aos elementos em comum, presentes em diferentes situações que podem ser consideradas estranhas. Através da psicanálise, Freud nos guia até o que pode ser visto como a origem do estranho. Dentre as causas do estranho relatadas por Freud, elegemos elementos em duas categorias dentro da novela de Melville: os elementos estranhos de ordem secundária (de menos importância, que auxiliam na construção do tom bizarro do texto de modo mais pontual) e os elementos estranhos de ordem primária (diretamente influenciados pelos elementos de ordem secundária e chave para o entendimento da nossa hipótese e texto). Começaremos abordando primeiramente os elementos de menor importância, pois são estes que colaboram para a construção do elemento estranho primordial abordado em seguida.

4 "Nothing so aggravates an earnest person as a passive resistance" (MELVILLE I856, p. IO).

5 "Poor fellow! thought I, he means no mischief; it is plain he intends no insolence; his aspect sufficiently evinces that his eccentricities are involuntary" (id. ibid.) 


\section{Elementos secundários}

Uma das questões que Freud aponta como reveladora de um estágio de estranheza é a incerteza intelectual. O estranho aparece, nesse caso, como algo que "não se sabe como tratar" (FREUD I969, p. 297). Tal definição não satisfaz Freud, que segue adiante com outras colocações. No entanto, essa mesma definição nos proporciona algumas considerações. A incerteza intelectual certamente não responde a todas as perguntas e ao grande tom de estranheza presente na história (pois este é um elemento de ordem secundária), mas podemos, talvez, entender o estranhamento que o narrador tem diante da situação que viveu.

Devemos nos lembrar do papel do narrador enquanto personagem. Além de chefe de Bartleby e de mais três outros funcionários, ele é um "homem da lei", um advogado. Dentro de sua lógica, um funcionário recém-chegado que não obedece às ordens que lhe são colocadas e que simplesmente repete um mesmo jargão a todo e qualquer pedido foge da ordem de qualquer razão. Num primeiro momento, ele simplesmente acredita que Bartleby pode não ter ouvido seu pedido e repete-o em vão, recebendo um "I would prefer not to" em resposta. Numa segunda ocasião, diante de outro pedido, o advogado chega a duvidar de si próprio, questionando os outros funcionários se ele não estava com a razão: "Não são raros os casos em que um homem intimidado de uma maneira irracional e sem precedentes tenha suas crenças mais básicas abaladas. [...] Consequentemente, se há quaisquer pessoas desinteressadas presentes, ele se vira para elas em busca de algum reforço para seu próprio pensamento hesitante."6

Sendo assim, a incerteza intelectual aparece como uma das causas do estranhamento presente na história, mas não a única. Devemos considerar também outros dois elementos de categoria secundária: a mecanização e a repetição. Embora apareçam em diferentes momentos no ensaio de Freud, se conectam dentro do nosso ensaio e da história.

A mecanização aparece como estranha porque ela suscita a sensação de dúvida se determinado ser aparentemente animado está vivo. Freud cita bonecos de cera e bonecos autômatos como exemplo: "processos automáticos e mecânicos operando por trás da aparência comum de atividade mental” (id. ibid., p. 7).

6 "It is not seldom the case that when a man is browbeaten in some unprecedented and violently unreasonable way, he begins to stagger in his own plainest faith. [...] Accordingly, if any disinterested persons are present, he turns to them for some reinforcement for his own faltering mind" (MELVILLE I856, p. 8). 
A repetição, por sua vez, surge na atmosfera do estranho através de sua predominância no inconsciente. Segundo Freud (id. ibid., p. I2), existe uma compulsão à repetição oriunda de impulsos instintivos. É claro que, nesse caso, o fator de repetição depende da situação. Repetimos todos os dias certas expressões para as mesmas ou para diferentes pessoas e nem por isso estamos envoltos numa atmosfera estranha. Em Bartleby, the Scrivener, no entanto, a repetição aparece em todos os contextos possíveis. Além disso, a expressão repetida incansavelmente não faz muito sentido, além de indicar o estado quase vegetativo da personagem diante da vida. A repetição de "I would prefer not to" nas mais diversas situações dá a Bartleby um aspecto mecânico, quase de ser inanimado, um semivivo passivo a tudo. Seu comportamento mecânico, repetitivo, e sem vida não está somente associado ao uso da expressão "I would prefer not to". O narrador nos dá indícios do aspecto quase doentio de Bartleby desde quando o contrata: "Ainda hoje sou capaz de vê-lo - palidamente claro, tristemente respeitável e incuravelmente desamparado! Era Bartleby". ${ }^{7}$ Mas mesmo pálido e doentio, Bartleby é contratado justamente devido ao seu aspecto "tranquilo", que, na visão do narrador, funcionaria bem com os temperamentos volúvel e explosivo de seus outros dois funcionários, Turkey e Nippers. Depois de ser contratado e iniciar seu trabalho como escrivão, a personagem permanecia em seu estado vegetativo e mecânico, como nos diz o narrador: "Inicialmente, Bartleby realizava uma quantidade extraordinária de trabalho. [...] Mas ele escrevia em silêncio, de maneira mecânica e apática." 8

Esses três elementos de ordem secundária na nossa análise, auxiliam na construção do efeito do estranho. Agora podemos, então, passar aos elementos de ordem primária que abrigam todos os outros elementos e são primordiais para o nosso entendimento do texto.

\section{Elementos primários: a morte e o narrador}

Como vimos acima, a repetição e a mecanização de Bartleby atribuem ao personagem um aspecto de semivivo, de um ser inanimado a respeito do qual ficamos em dúvida sobre o que exatamente ocorre por trás da "aparência comum de atividade mental" (FREUD ig69, p. 7). Essa dúvida gera também a incerteza intelectual (elemento de ordem primária), já mencionada acima.

7 "I can see that figure now - pallidly neat, pitiably respectable, incurably forlorn! It was Bartleby" (MELVILLE I856, p. I5).

8 "At first Bartleby did an extraordinary quantity of writing. [...] But he wrote on silently, palely, mechanically" (id. ibid., p. 6). 
Todos esses elementos geram algumas dúvidas sobre a maneira como a história está sendo contada pelo narrador.

Não é coincidência que a aparência de Bartleby seja relatada como "pálida", "incurável", e que seu comportamento se assemelhe ao de um ser sem vida, inanimado. Bartleby já está morto. Numa segunda leitura, após sabermos o trágico desfecho da história do escrivão, sabemos que este já estava morto durante a narrativa e, provavelmente, muito antes desta. No momento em que a história nos é contada, já parece haver passado algum tempo desde o encontro do narrador com Bartleby. Toda a narrativa é feita no passado e a alusão à vida do narrador, "um homem já de certa idade" (MELVILLE I856, p. I), que diz ter encontrado muitas pessoas singulares em sua trajetória, indica que Bartleby foi uma dessas pessoas que passou pela vida do advogado há algum tempo.

Se levarmos em conta, então, que durante toda a narrativa existe a consciência por parte do narrador de que Bartleby está morto, podemos entender não só a aparência semiviva e doentia que o escrivão ganha ao longo da história, mas também o tom de misericórdia assumido pelo narrador diante das atitudes de Bartleby. Para Freud (I969, p. I7), a morte é um dos fatores que compreende algo como sendo estranho, assustador e amedrontador. Tais sensações provêm de um primitivo medo e da insuficiência científica a respeito dela. No entanto, nossas atitudes em relação à morte, que já foram as mais diversas (crenças em seres sobrenaturais, fantasmas, mortos-vivos), sofreram uma repressão e uma redução a um sentimento de piedade para com os mortos. Explica-se aí a aparente piedade do narrador por Bartleby, ao narrar a história do falecido. Mesmo depois das diversas vezes que Bartleby se nega a ajudar em tarefas no trabalho, mesmo quando o advogado descobre que Bartleby está morando em seu escritório, mesmo após o escrivão se negar tanto a trabalhar quanto a deixar o escritório, mesmo depois de todos esses episódios, o advogado parece não alimentar sentimentos de raiva ou ódio por Bartleby, só pena. Quer dizer, ao menos é isso que o narrador nos diz.

\section{v. O narrador}

Como foi dito acima por Deleuze, "Talvez Bartleby seja o louco, o demente, o psicótico [...]. Mas como sabê-lo, se não se levam em conta as anomalias do advogado [...]?" (DELEUZE I997b, p. 87). Tendo ainda "O estranho", de Freud, como base, abordaremos agora o elemento tido como causa primordial do que é estranho e que dá nome ao título original do texto, "Das Unheimlich". 
Na definição do texto, o estranho aparece como algo essencialmente familiar, que foi submetido à repressão e que depois volta devido a algum tipo de estímulo oriundo da realidade psíquica ou material. "Essa referência ao fator da repressão permite-nos, ademais, compreender a definição de Schelling do estranho como algo que deveria ter permanecido oculto mas veio à luz." (FREUD ig69, p. I6).

Tendo isso em conta, devemos agora pensar no narrador, o advogado, como fonte de toda e qualquer informação que obtemos da história. Sendo um narrador-personagem e não um narrador em terceira pessoa onisciente, por exemplo, ele nos apresenta uma versão da história completamente moldada à sua visão.

É interessante nos lembrar das palavras do próprio narrador ao anunciar o início da história de Bartleby: "Antes de apresentar o escrivão, do modo como ele surgiu em minha vida, é pertinente que eu fale de mim [...]. Isso porque tal descrição é indispensável para uma compreensão adequada do personagem principal que está prestes a ser conhecido". ${ }^{9} \mathrm{Ou}$ seja, ele nos diz que para entender Bartleby devidamente devemos, primeiramente, entender ele próprio, o narrador.

Cabe também lembrar que durante praticamente toda a história, o narrador demonstra um comportamento inativo, exageradamente pacífico, e faz várias ressalvas, declarando seu temperamento "calmo" diante da vida: "Embora a minha profissão seja energética e nervosa, [...] nada desse tipo jamais chegou a prejudicar a minha paz", ${ }^{10}$ ou "Eu raramente me descontrolo; mais raramente ainda deixo transparecer perigosas indignações com injustiças e arbitrariedades". ${ }^{\text {II }}$

De fato, nada parece causar grandes emoções ou ações no advogado, mesmo injustiças e arbitrariedades. Antes de Bartleby aparecer, ele contava com outros dois escrivães em seu escritório em Wall Street, que devido a problemas de "temperamento" eram inúteis durante parte do dia, de manhã ou à tarde. No entanto, ele prefere ignorar esses "pequenos" problemas e permanecer com os dois funcionários. "Por essas razões, eu estava disposto a fazer

9 "Ere introducing the scrivener, as he first appeared to me, it is fit I make some mention of myself [...] because some such description is indispensable to an adequate understanding of the chief character about to be presented" (MELVILLE I856, p. I). Io "Hence, though I belong to a profession proverbially energetic and nervous [...] yet nothing of that sort have I ever suffered to invade my peace" (id. ibid., p. I).

II "I seldom lose my temper; much more seldom indulge in dangerous indignation at wrongs and outrages" (id. ibid., p. I). 
vistas grossas a suas excentricidades", ${ }^{12}$ diz o narrador a respeito de um dos seus dois funcionários que só trabalham durante um período do dia.

O mesmo acontece com Bartleby durante algum tempo. Mesmo depois dos diversos "I would prefer not to", o narrador não consegue despedir Bartleby facilmente e chega a deixar que este fique morando no escritório mesmo sem fazer nada. Essa situação extrema, que o narrador o deixa levar, diz muito sobre ele e também sobre Bartleby.

Talvez Bartleby seja estranho com sua resiliência e passividade porque o narrador também o é. Se levarmos em consideração o "Unheimlich" de Freud, o estranho familiar, poderemos entender de onde vem tal fascínio e horror por parte do narrador. Seu estranhamento proveniente do reconhecimento de suas próprias características no outro é o que chega até nós leitores. É possível, como diz Deleuze, que haja uma relação de identificação entre o advogado e Bartleby:

Na maioria das vezes, uma identificação parece colocar em jogo três elementos, que são capazes de trocar ou permutar: uma forma, imagem ou representação, um retrato, um modelo, um sujeito (ou, pelo menos, um sujeito virtual), um esforço do sujeito a assumir uma forma, se apropriar da imagem, para adaptar-se a essa imagem e imagem para si mesmo. ${ }^{13}$

A identificação entre Bartleby e o narrador gera exatamente o que coloca Deleuze: troca e apropriação da imagem e adaptação à imagem em si. Vemos isso claramente ao longo da história quando o narrador e os outros escrivães parecem se "contaminar" pela expressão do Bartleby: "so you got the word too?", diz o advogado para seu funcionário Turkey, que começa a dizer "I would prefer not to" também. O absurdo e ápice a que chega a novela, fazendo com que o narrador mude o escritório de lugar, já que Bartleby não quer sair, e o fim trágico de Bartleby, morto inerte na prisão, indicam um novo início para o narrador e para aquilo que ele representa. Se havia uma projeção pessoal por parte dele em Bartleby, como parece haver, e se a morte de Bartleby for tida como o parricídio final da tragédia edipiana, podemos pensar que um novo homem foi criado a partir daí, o homem americano.

12 "For these reasons, I was willing to overlook his eccentricities" (id. ibid., p. 3).

I3 "Most often, an identification seems to bring into play three elements, which are able to interchange or permutate: a form, image, or representation, a portrait, a model; a subject (or at least a virtual subject); and the subject's efforts to assume a form, to appropriate the image, to adapt itself to this image and the image to itself" (DELEUZE i997a, p. 76). 
Deleuze, embora discorde da psicanálise como explicação para o romance americano, este que, para o filosófo, dá luz a absurdos e permanece longe das explicações racionais da psicanálise, longe da neurose racional europeia, parece concordar com este nascimento do homem americano: "O advogado de Melville, Bartleby, assim como Kafka, deve encontrar o lugar onde pode seguir os seus próprios passos... América. O americano é aquele que está livre da função paterna inglesa, o filho de um pai que ruiu, o filho de todas as nações." "\4

Bartleby não constitui o papel exato de um pai aqui; ao contrário, o advogado é que parece exercer toda a sua ajuda e cuidado para com Bartleby, até determinado ponto. O que podemos visualizar, no entanto, é uma relação de identificação muito grande, na qual os próprios medos são visíveis no outro. Como já dissemos, parte da atmosfera estranha presente na história é oriunda das projeções do narrador em Bartleby. Sua morte, então, constitui não só uma espécie de sacrifício que auxilia na formação de um novo homem e de uma nova nação, mas a morte de todos os medos e repressões de um homem ficando livre dos fantasmas que possuía. Bartleby morre para que o narrador possa recriar a si mesmo, para que possa narrar uma nova história, a sua história disfarçada na história de Bartleby.

Para concluirmos, é necessário dizer que a mesma lógica aplicada ao nascimento desse novo homem pode ser aplicada para explicar o nascimento de uma nova literatura. A literatura livre de imposições e fantasmas presentes nas próprias relações da sociedade norte-americana influenciada pelo dogmatismo inglês. Como diz Deleuze: "Nós entendemos a novidade do pensamento americano quando vemos o seu pragmatismo como uma tentativa de transformar o mundo, de pensar um mundo novo, ou novo homem na medida em que criam a si próprios". ${ }^{5}$ E é com o pragmatismo de Bartleby, que insiste em não fazer nada, com o do narrador e advogado, que procura se recriar, e com o de Melville, que elabora uma história a respeito dos estranhos aspectos da natureza humana e da sociedade norte-americana, que o nascimento de uma literatura livre da neurose racional europeia, mas psicótica e absurda em si mesma, acontece.

I4 "Melville's bachelor, Bartleby, like Kafka's must find the place where he can take his walks'... America. The American is one who is freed from the English paternal function, the son of a crumbled father, the son of all nations" (id. ibid., p. 85).

15 "We understand the novelty of American thought when we see pragmatism as an attempt to transform the world, to think a new world or new man insofar as they create themselves" (id. ibid., p. 86). 


\section{Referências bibliográficas}

DELEUZE, Gilles. Bartleby; or, the Formula". In: Essays Critical and Clinical. Minneapolis: University of Minneapolis Press, I997a, pp. 68-90.

. Bartleby, ou a fórmula. In: Crítica e Clínica. Tradução Peter Pál Pelbart. São Paulo: Editora 34, I997b, pp. 80-II4.

MELVILLE, Herman. Bartleby, the Scrivener: a Story of Wall Street. Columbia, I856. Disponível em: 〈http://moglen.law.columbia.edu/LGS/bartleby.pdf〉. Acesso em: I8 ago. 20I4.

FREUD, Sigmund. O estranho. In: . História de uma neurose infantil. ESB, v. XVII. Rio de Janeiro: Imago, I969.

The Life and Works of Herman Melville. Disponível em: <http://www.melville.org/melville. $\mathrm{htm}>$. Acessado em: I4 out. 2013.

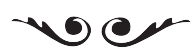

Carlos Henrique Francisco de Amorim Santos - Graduando em Letras pela Universidade de São Paulo. cahenriq@gmail.com 